\title{
Erratum to: Links between soil texture and root architecture of Eucalyptus species may limit distribution ranges under future climates
}

\author{
Jason J. Hamer • Erik J. Veneklaas • Michael Renton • \\ Pieter Poot
}

Published online: 6 October 2015

(C) Springer International Publishing Switzerland 2015

\section{Erratum to: Plant and Soil \\ DOI:10.1007/s11104-015-2559-5}

There was a mistake in the presentation of Leaf Mass per Area (LMA) values in Figure 3. Y axis labels should be 100 times that originally presented. Please see the below figure for the correct presentation of the data. Axis values for the figure were manually entered incorrectly, while the actual values used in analyses were correct. As such, there is no change to the interpretation of these data throughout the article.

The online version of the original article can be found at http://dx. doi.org/10.1007/s11104-015-2559-5

J. J. Hamer · E. J. Veneklaas · M. Renton · P. Poot The University of Western Australia, School of Plant Biology (M090), 35 Stirling Highway, Crawley, Western Australia, Australia 6009

J. J. Hamer $(\bowtie) \cdot$ E. J. Veneklaas $\cdot$ M. Renton $\cdot$ P. Poot Centre of Excellence for Climate Change, Woodland and Forest Health, Western Australia, Australia

e-mail: 2j.hamer@gmail.com 

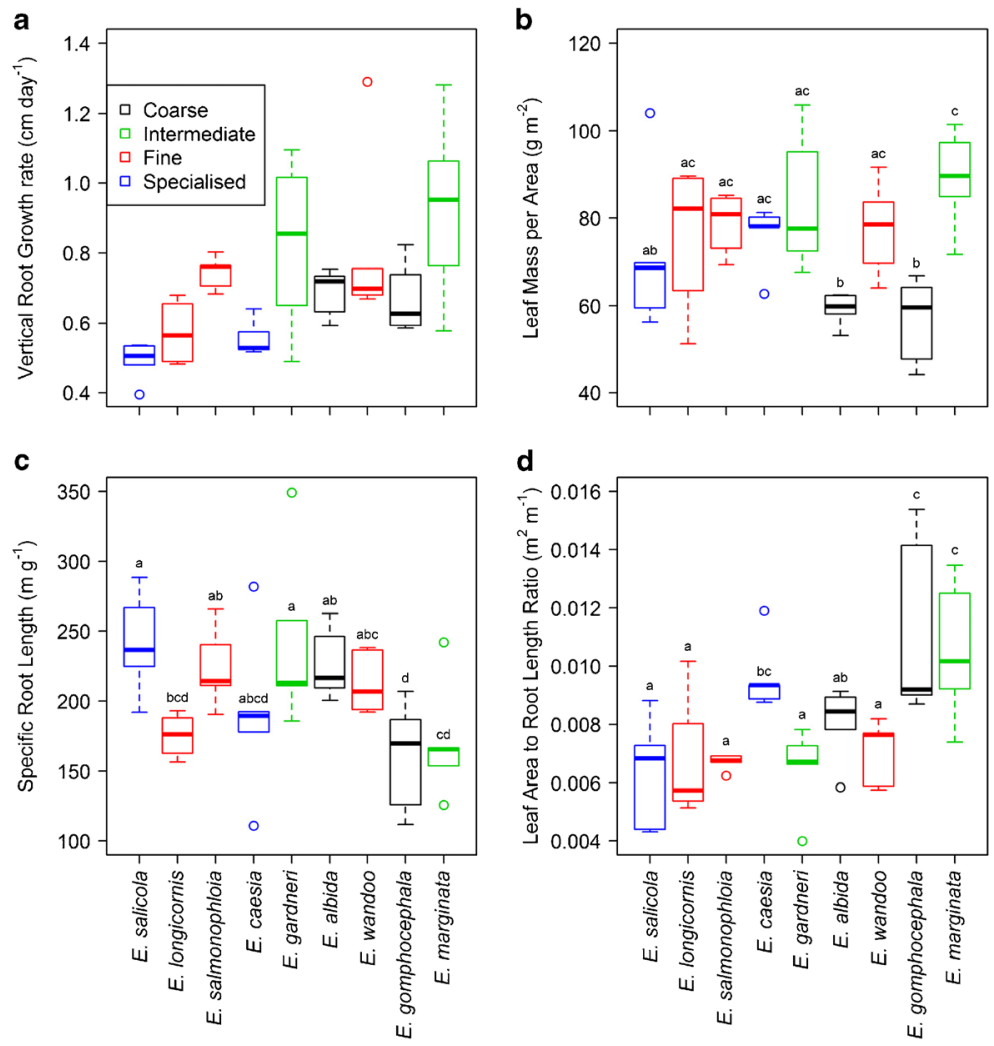